\title{
USO DA FERRAMENTA PERT/CPM NO SERVIÇO DE MANUTENÇÃO DE EQUIPAMENTOS SUBMARINOS
}

\author{
Jéssica Siqueira de Almeida \\ Graduada em Engenharia de Produção / ISECENSA \\ Jessica_sia@hotmail.com
}

\section{RESUMO}

O petróleo é um recurso de grande valor econômico, pois é fonte de energia primária e um dos principais itens de exportação. A atividade de exploração e produção de petróleo atraiu muitas empresas que estão cada vez mais investindo em equipamentos de alta tecnologia e automação. Nesta perspectiva, máquinas e equipamentos de qualidade e de resposta rápida à superfície se tornaram imprescindíveis. Apesar do alto investimento, a inovação desses equipamentos é muito rentável para as empresas e o retorno financeiro na manutenção desses equipamentos é, também, muito vantajoso. Diante deste cenário promissor, algumas empresas visualizaram a importância de buscar a qualidade total em serviços de manutenção de equipamentos de produção e exploração de petróleo e gás, utilizando este serviço como função estratégica para a disponibilidade dos ativos que são de suma importância para a indústria petrolífera. Esta pesquisa tem como objetivo fazer um estudo da utilização da técnica de planejamento e controle PERT/CPM no processo de manutenção de equipamentos offshore. Foi realizado um estudo de caso e a pesquisa foi aplicada em uma empresa que presta serviço de manutenção em equipamentos submarinos no município de Macaé, estado do Rio de Janeiro. Para o desenvolvimento da pesquisa foram coletados dados e a partir desses foi elaborado o diagrama PERT e calculado o CPM. Ao final do estudo, percebeu-se que a utilização desta técnica é viável no sentido de planejar e controlar as atividades referentes a manutenção, a fim de cumprir-se com a entrega do equipamento no prazo estabelecido.

Palavras - chave: petróleo; planejamento; manutenção; PERT/CPM.

\section{ABSTRACT}

Oil is a resource of great economic value, because it is a primary source of energy and also a major export. Oil exploration and production has attracted many companies that have been increasingly investing in high-tech equipment and automation. In this perspective, quality machinery and equipment with quick response times have become indispensable. Despite the high investment, innovation in such equipment is very profitable for the companies and the financial return in the maintenance of such equipment is also very advantageous. Given this promising scenario, some companies have perceived the importance of providing total quality services regarding the maintenance of oil and gas production and exploration equipment, thus using this service as a strategy to increase the availability of assets that are of paramount importance for the oil industry. This research aims to study the use of PERT / CPM, a planning and control technique, in the maintenance process of offshore equipment. A case study was carried out and the survey was done in a company located in the city of Macaé, Rio de Janeiro, that provides maintenance services for subsea equipment. To develop the research, data was collected and in turn the PERT diagram was created and the CPM was calculated. The study was able to perceive that the use of this technique is feasible to plan and control activities related to maintenance, so as to comply with the delivery of the equipment on time.

Keywords: oil, planning, maintenance, PERT / CPM.

Persp. online: exatas. \& eng, Campos dos Goytacazes, 10 (4), 43-65, 2014

seer.perspectivasonline.com.br 


\section{INTRODUÇÃO}

Segundo Thomas (2004), grandes somas de recursos econômicos e humanos mobilizam-se para sustentar as operações de exploração e produção de óleo e gás no Brasil e no mundo. E, com o crescimento das reservas de óleo e gás, a relação Reserva versus Produção dá um grande impulso para o crescimento brasileiro.

De acordo com a Petrobrás (2009), o objetivo da mesma é aumentar a capacidade de produção das refinarias para atender a crescente demanda de derivados do petróleo e com a tecnologia desenvolvida para processar o petróleo nacional, que tem como característica ser bastante pesado, o resultado é uma maior quantidade de produtos saindo das refinarias diminuindo a dependência da importação e aumentando a rentabilidade. Segundo Kardec e Lafraia (2002), a atividade de exploração e produção de petróleo é composta pelas atividades de operação, manutenção e engenharia. Desta maneira, o foco do trabalho será dado à uma empresa que realiza a atividade de manutenção de equipamentos de exploração e produção de petróleo.

Ainda para Kardec e Lafraia (2002), a missão da atividade de manutenção é garantir a funcionalidade dos equipamentos e, consequentemente, a disponibilidade dos mesmos. Desta forma, em um mercado competitivo, as empresas de manutenção devem oferecer aos seus clientes a disponibilidade dos equipamentos, confiabilidade, custos adequados, qualidade e segurança.

De maneira a atender às exigências dos clientes, uma empresa que presta serviço de manutenção em equipamentos da área de exploração e produção de petróleo deve gerenciar esta atividade e, segundo Branco Filho (2008), gerenciar a manutenção é definir metas e objetivos de acordo com normas e procedimentos de trabalho para obter um melhor aproveitamento de pessoal, máquinas e materiais.

Para que sejam executadas corretamente, além de gerenciadas, as atividades de manutenção de equipamentos devem ser planejadas, programadas e controladas e a importância do planejamento é para que as tarefas ocorram dentro dos critérios aceitáveis e desejados (BRANCO FILHO, 2008). Segundo Slack et al. (2009), o planejamento e o controle ocupam-se de gerenciar as atividades da operação produtiva de modo a satisfazer continuamente a demanda dos consumidores.

Este estudo irá abordar o planejamento e controle da produção como forma de auxiliar o processo de manutenção de equipamentos offshore, através da utilização da técnica PERT/CPM para planejar, sequenciar e acompanhar as atividades e de forma a atender os clientes no prazo estabelecido com qualidade e custos acessíveis, já que, uma parada de produção em um ambiente petrolífero por indisponibilidade de equipamentos ou falha causaria grandes prejuízos econômicos e financeiros aos clientes.

Em uma empresa que faz manutenções em equipamentos de produção e exploração de petróleo, diversos gargalos referentes a suprimentos, espaço físico, mãos-de-obra atrasam a liberação desses equipamentos para os clientes.

Considerando que este mercado é muito competitivo e um pequeno atraso pode gerar um prejuízo gigantesco, o maior desafio é gerenciar a manutenção dos equipamentos e o planejamento dos recursos para que a atividade seja atendida dentro do prazo estabelecido nos contratos de trabalho.

Atualmente, as empresas se deparam com a dificuldade de conciliar qualidade, prazo e custo de forma eficiente. Com isso, saber utilizar os instrumentos de planejamento de forma coerente, adaptando-os à realidade da empresa e às suas necessidades pode ser uma excelente estratégia competitiva.

Slack et al. (2009) citam que o propósito do planejamento é garantir que a produção ocorra de forma eficaz e que esta produza produtos e serviços como deve. Diante disto, uma possível solução seria a aplicação da ferramenta de planejamento e controle PERT/CPM a fim de planejar, programar e controlar as atividades de manutenção para que se consiga alinhar qualidade, custo e prazo.

Persp. online: exatas. \& eng, Campos dos Goytacazes, 10 (4), 43-65, 2014

seer.perspectivasonline.com.br 
Este trabalho tem como objetivo geral fazer um estudo de viabilidade técnica da utilização da ferramenta de planejamento PERT/CPM em uma empresa que realiza manutenções em equipamentos para a exploração e produção de petróleo e gás, visando propor a utilização da referida ferramenta no processo de manutenção de equipamentos submarinos como forma de melhorar o planejamento e o controle das atividades de manutenção a fim de que tais equipamentos sejam entregues aos clientes nos prazos previamente acordados.

\section{METODOLOGIA}

Essa pesquisa pode ser considerada como aplicada, pois tem o objetivo de gerar conhecimento para aplicação prática para solucionar problemas específicos, envolvendo verdades e interesses locais (SILVIA \& MENEZES, 2005).

Do ponto de vista da abordagem do problema, considera-se a pesquisa qualitativa, pois é elaborada a partir da interpretação de fenômenos, onde o ambiente natural é a fonte da coleta de dados (SILVIA \& MENEZES, 2005). Desta forma, a pesquisa acontece através da observação do processo de manutenção dos equipamentos da empresa, obtendo sua interpretação e análise dos dados obtidos. É necessário destacar que esta pesquisa faz uma avaliação quantitativa por utilizar a técnica de planejamento e controle PERT/CPM no processo de manutenção, ou seja, traduzindo, em números, informações que posteriormente serão classificadas e analisadas (SILVIA \& MENEZES, 2005).

De acordo com Gil (1991 apud SILVIA \& MENEZES, 2005), quanto aos objetivos, a pesquisa caracteriza-se como exploratória, pois busca explorar a situação-problema vivenciada na empresa, criar hipóteses para melhoria do processo de manutenções, envolvendo levantamento bibliográfico.

Quanto aos procedimentos técnicos, a pesquisa mostra-se como bibliográfica, pois o embasamento teórico para a aplicação de uma técnica de planejamento e controle no gerenciamento da manutenção de equipamentos será elaborada a partir de materiais já publicados. E o trabalho também consiste em um estudo de caso, pois envolve o estudo de uma empresa específica (GIL, 1991 apud SILVIA \& MENEZES, 2005).

\subsection{Procedimentos Técnicos}

Para realização do trabalho, serão listadas em uma tabela todas as atividades realizadas desde a entrada do equipamento na fábrica para a manutenção até a sua liberação pelo controle de qualidade da empresa, bem como as relações de dependência entre as mesmas e o tempo de duração de cada atividade como exemplifica a tabela 1.

Tabela 1: As atividades e suas relações de precedência.

\begin{tabular}{|c|c|c|c|}
\hline SIGLA & ATIVIDADE & TEMPO & RELAÇ̃̃O DE DEPENDÊNCIA \\
\hline A & 1 & $10 \mathrm{~h}$ & - \\
\hline B & 2 & $5 h$ & $\mathrm{~A}$ \\
\hline $\mathrm{C}$ & 3 & $8 \mathrm{~h}$ & $\mathrm{~A}$ \\
\hline $\mathrm{D}$ & 4 & $3 \mathrm{~h}$ & $\mathrm{~A}, \mathrm{C}$ \\
\hline $\mathrm{E}$ & 5 & $5 \mathrm{~h}$ & $\mathrm{~B}$ \\
\hline $\mathrm{F}$ & 6 & $1 \mathrm{~h}$ & $\mathrm{D}, \mathrm{E}$ \\
\hline $\mathrm{G}$ & 7 & $2 \mathrm{~h}$ & $\mathrm{C}, \mathrm{F}$ \\
\hline
\end{tabular}

Fonte: Elaboração própria, 2012.

Persp. online: exatas. \& eng, Campos dos Goytacazes, 10 (4), 43-65, 2014

seer.perspectivasonline.com.br 
Com base nesta tabela, será elaborado o diagrama de rede PERT, de forma a definir e integrar as atividades referentes a manutenção. Para criação desta rede, serão utilizados nós para representar as atividades e os arcos para representar as relações de precedência entre as atividades, como mostra a figura 11 abaixo.

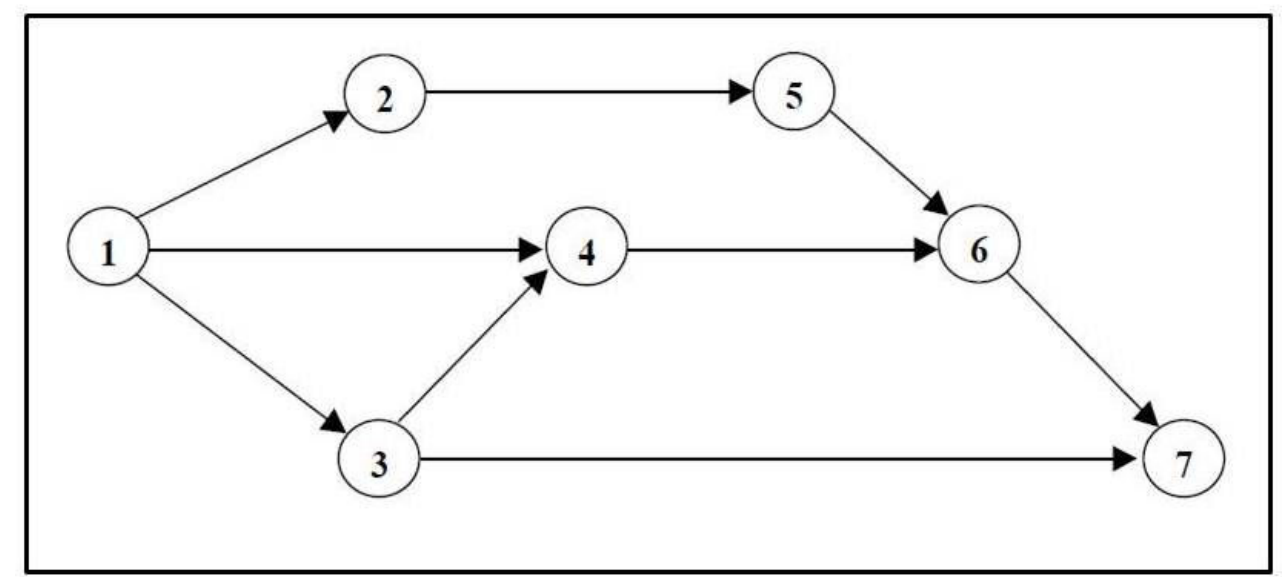

Figura 1: Diagrama PERT. Fonte: UFRRJ, 2012.

A partir de então, serão definidos possíveis caminhos para a realização da manutenção, ou seja, rotas que seguem os arcos a partir do nó Início até o nó Fim. A fim de definir o caminho crítico serão somados os tempos de todas as atividades de todos os possíveis caminhos definidos anteriormente. Desta forma, o caminho crítico será o caminho com maior comprimento o que definirá, também, as atividades críticas do projeto.

Com esse diagrama de rede PERT definido, será calculado o CPM, o caminho crítico do projeto utilizando-se as variáveis abaixo:

- ES (Tempo Inicial Mais Cedo, em inglês, Early Start) - é igual ao maior tempo final mais cedo das atividades precedentes;

- EF (Tempo Final Mais Cedo, em inglês, Early Finish) - é o tempo inicial mais cedo desta atividade somado a duração da atividade;

- LS (Tempo Inicial Mais Tarde, em inglês, Late Start) - é o tempo final mais tarde somado a duração da atividade;

- LF (Tempo Final Mais Tarde, em inglês, Late Finish) - é igual ao menor tempo inicial mais tarde das atividades sucessoras.

O Tempo Inicial Mais Cedo (ES) e o Tempo Final Mais Cedo (EF) serão calculados do nó início para o nó fim e o Tempo Inicial Mais Tarde (LS) e o Tempo Final Mais Tarde (LF) serão calculados do nó fim para o nó início.

O cálculo do caminho crítico também inclui o cálculo de folga entre as atividades, o tempo em que uma atividade pode atrasar sem atrasar a duração total do processo. Essa variável folga é calculada conforme a fórmula abaixo:

$$
\begin{array}{|l|l|}
\hline \text { FOLGA (S): } & \text { LS - ES } \\
\cline { 2 - 2 } & \text { LF - EF } \\
\hline
\end{array}
$$

Persp. online: exatas. \& eng, Campos dos Goytacazes, 10 (4), 43-65, 2014

seer.perspectivasonline.com.br 
O cálculo do caminho crítico e da folga entre as atividades auxiliará na programação das atividades, ou seja, determinar quando (em que dia, em qual semana, por exemplo) uma atividade deverá começar e terminar, definindo, então, todo o processo de planejamento, programação e controle do processo de manutenção do equipamento.

\subsubsection{Coleta de Dados}

Para a realização dos procedimentos técnicos será simulado o processo de manutenção de um equipamento que faz parte da liberação de um sistema para o cliente a partir dos dados fornecidos pela tabela de periodicidade de manutenção estabelecida no plano de manutenção como exemplifica a figura abaixo.

\begin{tabular}{|c|c|c|c|c|c|}
\multirow{2}{*}{ Descrição } & \multicolumn{3}{|c|}{$\begin{array}{c}\text { Manutenção } \\
\text { Preventiva }\end{array}$} & \multicolumn{2}{c|}{$\begin{array}{c}\text { Manutenção } \\
\text { Corretiva }\end{array}$} \\
\cline { 2 - 6 } & TO & NUT & TA & TO & NUT \\
\hline Item 1 - EQUIPAMENTO A & $6 \mathrm{M}$ & 16 & $6 \mathrm{M}$ & $24 \mathrm{M}$ & 60 \\
\hline Item 2 - EQUIPAMENTO B & $6 \mathrm{M}$ & 16 & $6 \mathrm{M}$ & $24 \mathrm{M}$ & 60 \\
\hline Item 3 - EQUIPAMENTO C & $6 \mathrm{M}$ & 16 & $6 \mathrm{M}$ & $24 \mathrm{M}$ & 60 \\
\hline Item 4 - EQUIPAMENTO D & $6 \mathrm{M}$ & 16 & $6 \mathrm{M}$ & $24 \mathrm{M}$ & 40 \\
\hline Item 5 - EQUIPAMENTO E & $6 \mathrm{M}$ & 16 & $6 \mathrm{M}$ & $24 \mathrm{M}$ & 40 \\
\hline Item 6 - EQUIPAMENTO F & $6 \mathrm{M}$ & 16 & $6 \mathrm{M}$ & $24 \mathrm{M}$ & 40 \\
\hline Item 7 - EQUIPAMENTO G & $6 \mathrm{M}$ & 16 & $6 \mathrm{M}$ & $24 \mathrm{M}$ & 40 \\
\hline Item 8 - EQUIPAMENTO H & $12 \mathrm{M}$ & $\mathrm{N} / \mathrm{A}$ & $12 \mathrm{M}$ & $12 \mathrm{M}$ & $\mathrm{N} / \mathrm{A}$ \\
\hline
\end{tabular}

Quadro 1: Periodicidade da manutenção dos equipamentos. Fonte: Elaboração própria, 2012.

Baseando-se na manutenção preventiva do equipamento A que operou durante mais de seis meses e chegou à base, foi feita uma ordem de serviço de preventiva, ao qual, foi gerado um relatório de avarias feito pela produção, pois o equipamento apresentou falhas durante os testes, solicitando os seguintes serviços para o reparo do equipamento:

- Desmontagem localizada;

- Substituição de peças fabricadas e comerciais;

- Reparo das peças desmontadas;

- Montagem localizada;

- Caldeiraria;

- Pintura;

- Testes.

Após a confecção do relatório de avarias pela produção serão emitidas ordens de reparo do equipamento, ordens de compra e fabricação de peças e, também, ordens de reparo de componentes.

Desta forma, para que se possa prever a liberação do equipamento serão considerados os seguintes requisitos:

- O lead time de reparo das peças que necessitam ser reparadas de acordo com o relatório de avarias;

- Lead time das peças de fabricação e comerciais;

Persp. online: exatas. \& eng, Campos dos Goytacazes, 10 (4), 43-65, 2014

seer.perspectivasonline.com.br 
- Tempo que a produção leva para realizar a montagem e a desmontagem do equipamento;

- Tempo que a produção leva para realizar os testes do equipamento após a manutenção;

- Tempo para a liberação do equipamento para o cliente.

Com as informações acima, serão listadas todas as atividades referentes a manutenção do equipamento tanto na área de produção (fabril) quanto na área de planejamento e suas respectivas durações e relações de precedência, a fim de se ter dados concretos para o desenvolvimento do presente trabalho.

\subsection{Análise dos resultados}

A análise dos resultados se dá através da avaliação do diagrama PERT e o cálculo do CPM nas atividades de manutenção do equipamento específico escolhido. Considera-se esta técnica PERT/CPM como uma técnica de planejamento, programação e controle no processo de manutenção.

\section{CONTEXTUALIZAÇÃ̃O}

\subsection{Produção de Petróleo}

A atividade de exploração de petróleo no Brasil começou em 1858 quando o Marquês de Olinda, através de um decreto, concedeu o direito de extração de petróleo para a produção de querosene. A partir de então, muitos poços foram perfurados até que em 1941 foi descoberto o primeiro campo comercial na Bahia e em 1970 foi descoberto o campo de Garoupa na bacia de Campos, ao qual, deu início a produção (THOMAS, 2004).

$\mathrm{Na}$ década de 90 poços foram descobertos outros poços (THOMAS, 2004). Com a experiência adquirida no desenvolvimento de campos em águas profundas, o Brasil ficou em posição de destaque com a descoberta do Pré-Sal. E em 05 de março de 2012 a ANP (Agência Nacional do Petróleo, Gás Natural e Biocombustíveis) divulgou que o país registrou um recorde de produção em petróleo em janeiro de 2012 atingindo 2,23 barris em média por dia e que a produção do Pré-Sal neste mesmo mês foi de 152,3 barris por dia.

Essa crescente atividade de exploração e produção de petróleo envolve, também, as atividades de operação, manutenção e engenharia (KARDEC \& LAFRAIA, 2002), ao qual, o presente trabalho dará enfoque à atividade de manutenção na área petrolífera como garantidora da disponibilidade dos equipamentos, mantendo a funcionalidade e a confiabilidade dos mesmos.

\subsection{Manutenção}

Xavier e Pinto (2001) afirmam que o produto que a atividade de manutenção oferece é a maior disponibilidade confiável ao menor custo. Os autores Kardec e Lafraia (2002) dizem que atualmente, a missão da atividade de manutenção é "Garantir a disponibilidade da função dos equipamentos e instalações de modo a atender a um processo de produção ou serviço, com confiabilidade, segurança, preservação do meio ambiente e custo adequados".

Os tipos de manutenção referem-se às maneiras de intervenção em um equipamento que faz parte de um sistema ou de uma planta. (VIANA, 2002 apud CAMPOS JÚNIOR, 2006).

Para Branco Filho (2008) e Xavier e Pinto (2001), manutenção corretiva consiste em reparar as falhas que ocorrem em determinado equipamento, restaurando a funcionalidade do mesmo. A manutenção preventiva é uma ação para reduzir ou evitar a falha ou até queda de desempenho. E a manutenção preditiva Preditiva tem o objetivo de prevenir que ocorram falhas nos equipamentos através do acompanhamento de parâmetros, permitindo que o equipamento opere de forma contínua pelo maior tempo possível.

Persp. online: exatas. \& eng, Campos dos Goytacazes, 10 (4), 43-65, 2014 
Xavier e Pinto (2001) destaca a manutenção detectiva sendo aquela que busca detectar falhas que são cultas ou não perceptíveis e não será detalhada neste trabalho. Destaca, também, a Engenharia de Manutenção que é o tipo de atuação que busca as causas básicas das falhas para não ficar apenas consertando continuamente, ou seja, modificar o ambiente de problemas e de mau desempenho para melhorar os padrões e desenvolver a manutenibilidade. Quando a empresa passa a adotar a engenharia de manutenção, assume que deve manter os equipamentos e/ou sistemas disponíveis para atender o mercado, ao cliente, razão da sua existência e da manutenção (KARDEC \& LAFRAIA, 2002).

Xavier (1998) diz que as empresas de manutenção no Brasil enfrentam problemas como retrabalho, falta de mão-de-obra qualificada, falta de sobressalentes no estoque, número elevado de serviços não previstos, falta de planejamento prévio. Esses problemas causam não cumprimento de prazos, grande número de equipamentos em manutenção gerando baixa disponibilidade, grande número de manutenção corretiva não planejada.

Em um ambiente como a área petrolífera, a interrupção do processo para reparo de um equipamento pode comprometer a qualidade dos outros que estavam em condições funcionais, além de causar parada de produção. Respondendo a novos desafios que se apresentam, as empresas devem pensar e agir de maneira estratégica. Desta forma, a atividade de manutenção passou a fazer parte do processo produtivo contribuindo para que as organizações, como no caso do trabalho, empresas da área offshore, alcancem a excelência. Neste cenário, não deve haver improviso e, sim, competência e flexibilidade para garantir o seu espaço no mercado competidor Xavier e Pinto (2001).

O mesmo autor ainda afirma que utilizar a manutenção como função estratégica influencia diretamente nos resultados da empresa, pois aumenta da disponibilidade, aumentando o faturamento.

\subsection{Gerenciamento da Manutenção e o Planejamento e controle da manutenção}

A manutenção é um investimento e não uma despesa, pois mantem a disponibilidade do equipamento e o processo produtivo, motivo pelo qual existe a organização. E para tal, deve haver uma gestão da manutenção (CHIOCHETTA et al., 2004).

Assim, segundo Branco Filho (2008), a real finalidade da Gerência da Manutenção em uma empresa é definir metas e objetivos de acordo com normas e procedimentos de trabalho para obter um melhor aproveitamento de pessoal, máquinas e materiais. Desta maneira, as tarefas de manutenção devem ser executadas de maneira correta, já que, exigem planejamento, programação, alocação de recursos físicos e financeiros, treinamentos e qualidade, alinhando a execução da função manutenção à expectativa do cliente e à economia. A importância do planejamento é para que as tarefas ocorram dentro dos critérios aceitáveis e desejados.

Ainda para o mesmo autor, as vantagens obtidas com o Planejamento e Controle da manutenção são:

- Redução de perda de tempo da mão de obra direta;

- Aumento da eficiência da mão de obra direta;

- Padronização de procedimentos de execução de tarefas;

- Análise de desvios de metas e medidas de correção.

\subsection{Planejamento e controle da produção}

A principal função do Planejamento e Controle da Produção é adequar as decisões operacionais ás necessidades estratégicas da organização. (CORREIA \& GIANESI, 1997 apud LAGE JUNIOR, 2006). Segundo Tubino (2009), o Planejamento e Controle da Produção coordena, aloca e aplica os recursos de produção de forma a atender os planos definidos a nível estratégico, tático e operacional pela organização.

Melo et al. (2006) listam as funções do Planejamento e Controle da Produção como sendo:

Persp. online: exatas. \& eng, Campos dos Goytacazes, 10 (4), 43-65, 2014

seer.perspectivasonline.com.br 
- Gerir estoques;

- Emitir ordens para a produção;

- Programar as ordens;

- Acompanhar e controlar a produção.

O Planejamento e Controle da Produção é extremamente significante para o gerenciamento da produção, combinando fluxos físicos e de informações, definindo metas e identificando desvios na produção, mantendo os objetivos da organização. (SIPPER \& BULFIN, 1997 apud LAGE JUNIOR, 2006).

O foco da atividade de planejamento e controle da produção pode ser definido segundo planejamento, quando se produz para estoque, e segundo programação, quando se produz sob encomenda. Porém quando a produção é sob encomenda com alta variedade de produtos, o foco é tanto planejamento quanto programação (FERNANDES \& SANTORO, 2005 apud SOARES \& PEREIRA, p. 3, 2006).

\subsubsection{Planejamento estratégico da produção}

Decisões de longo prazo definidas pela empresa para alcançar o que foi definido na sua missão fazem parte do planejamento estratégico que tem como finalidade maximizar os resultados das operações e diminuir os riscos dessas decisões empresariais. Assim, planejar de forma estratégica faz com que a organização conheça suas forças e habilidades no mercado para decidir com rapidez e segurança diante de oportunidades e ameaças, aumentando sua vantagem competitiva (TUBINO, 2009).

O planejamento estratégico auxilia a empresa na definição do seu posicionamento no mercado competitivo, porém não derivam dele atividades diretas, mas sim planos que serão operacionalizados no nível de processos (MÜLLER, 2003, apud MENESES \& MÜLLER, p. 1, 2006).

Diz-se que o planejamento estratégico permite uma análise das perspectivas econômicas e também da concorrência. Ele ajuda na elaboração de um plano de ação a longo prazo que possibilita o detalhamento das atividades de curto prazo (DANTAS \& TÁVORA JÚNIOR, 2006). E dentre os planos de longo prazo definidos pelo planejamento estratégico, está o S\&OP (do inglês, Sales and Operation Planning) que tem como definição, planejamento de vendas e operações.

Para Correa et al. (2011) o planejamento de vendas e operações integra os diferentes níveis de decisão estratégicos e operacionais de forma a garantir que o que foi decidido estrategicamente a longo prazo seja operacionalizado.

O principal objetivo do S\&OP é gerar planos de vendas, produção, financeiro e de desenvolvimento de novos produtos viáveis e coerentes com os objetivos estratégicos organizacionais (CORREA et al., 2011). E esse objetivo é realizado através de reuniões, no qual, as informações enviadas pelos setores de finanças, engenharia, vendas e produção são discutidas e analisadas e ao final, os planos funcionais de cada área são aprovados (NAVARRO \& LIMA, 2006).

\subsubsection{Planejamento Mestre da produção}

O planejamento-mestre da produção é um programa de produção que define tudo aquilo que é fabricado pela empresa, expresso em quantidades e datas (RUSSOMANO, 2000 apud KERMER et al., 2006). Para Tubino (2009), a função do planejamento-mestre da produção é dividir os planos estratégicos de longo prazo em planos específicos de médio prazo para obter produtos acabados. Ou seja, definidas as estratégias, inicia-se o processo de programação e execução de atividades operacionais.

O planejamento-mestre da produção organiza os recursos internos da empresa de acordo com a demanda para programar de maneira adequada a produção dos produtos finais colaborando para um melhor gerenciamento de estoques de produtos acabados, uma melhoria no atendimento ao cliente no

Persp. online: exatas. \& eng, Campos dos Goytacazes, 10 (4), 43-65, 2014

seer.perspectivasonline.com.br 
prazo estabelecido e para uma maior segurança e rapidez na tomada de decisões para satisfazer a demanda e conquistar e/ou garantir sua posição no mercado competidor (CORREA et al, 2011).

Ainda o mesmo autor comenta que a importância de se fazer o planejamento-mestre da produção é que ele está ligado à gestão estratégica da organização, direcionando as metas mais amplas e de longo prazo. Porém, para que tais metas sejam alcançadas, é necessário que esse plano estratégico se divida em planos operacionais de vendas (definir a quantidade de unidades a serem vendidas), marketing (definir qual tipo de mercado atacar), engenharia (definir planos e projetos a serem desenvolvidos), finanças (definir receitas, despesas e lucros gerados) e manufatura (definir quais e quantos recursos serão utilizados) (CORREA et al, 2011).

No planejamento-mestre da produção é elaborado um plano-mestre de produção. Kremer et al (2006) afirmam que no plano - mestre de produção são descritas as quantidades planejadas de acordo com a demanda presente e a previsão de demanda futura e, também, os recursos atuais da empresa e os que ela pretende ter no futuro. O plano-mestre de produção estabelecido irá oficializar as decisões referentes à necessidade de produtos acabados. Esta análise auxilia na validação de que o sistema produtivo irá atender a demanda em médio prazo (TUBINO, 2009).

\subsubsection{Programação da produção}

A programação da produção está dentro do nível operacional de curto prazo e, baseada no plano-mestre de produção e no estoque existente, sua função é direcionar a quantidade e o tempo certo para compra, fabricação ou montagem de cada item necessário na composição dos produtos finais propostos no plano. Como resultado disso, são geradas ordens de fabricação, compra e montagem, tanto submontagens como montagem final do produto (TUBINO, 2009).

Para Kopak e Favaretto (2001), o processo de programar a produção consiste em programar as atividades de produção fazendo o sequenciamento das ordens de produção. O autor Slack (2009) afirma que o sequenciamento é gerado a partir de decisões tomadas sobre a ordem em que as atividades serão executadas, ou seja, a programação da produção define o momento em que as atividades devem começar e o momento em que elas devem terminar.

Com base no plano de produção, define-se o plano mestre da produção de produtos finais de acordo com a previsão de vendas e pedidos em carteira. A partir disto, o planejamento e controle da produção se encarrega de analisar os possíveis gargalos que possam tornar inviável a programação da produção a curto prazo. Sendo viável o planejamento mestre da produção e conhecendo-se os estoques e as informações de engenharia, a programação da produção estabelece quando e quando comprar, montar ou fabricar de cada item que compõe o produto final. Analisando-se a disponibilidade dos recursos produtivos, inicia-se o sequenciamento das ordens (KOPAK \& FAVARETTO, 2001).

O sistema produtivo adotado pela empresa em estudo é o sob encomenda. Nele, a programação da produção passa a dar foco na capacidade produtiva, emitindo e fazendo um acompanhamento das ordens para que o cliente seja atendido no prazo acordado (TUBINO, 2009).

Por se tratar de produtos exclusivos, no sistema produtivo sob encomenda, a programação da produção deve definir as operações que serão realizadas em cada ponto de trabalho. Assim, esta programação pode ser feita com base no gerenciamento de redes, através da ferramenta PERT/COM, de forma a identificar o caminho crítico que deve ser acompanhado para que o produto seja entregue ao cliente com qualidade e na data anteriormente negociada (TUBINO, 2009).

\subsection{Ferramenta PERT/CPM}

As etapas de um projeto são planejamento, onde se define o que irá ser feito através do detalhamento das atividades e da relação de interdependência entre elas, programação, onde as atividades serão colocadas na ordem temporal de execução, ou seja, através de um cronograma que determina o fim e o início das atividades, e controle, que ocorre durante todo o processo de execução

Persp. online: exatas. \& eng, Campos dos Goytacazes, 10 (4), 43-65, 2014

seer.perspectivasonline.com.br 
do projeto, definindo ações para que a programação estabelecida aconteça sem atrasos (LOE, 1999 apud KIENEN, 2000).

Tubino (2009) afirma que em projetos, a principal função do planejamento e controle da produção é organizar os recursos disponíveis para garantir a data de conclusão do projeto, sequenciando as tarefas de forma que o início e conclusão de algumas atividades estejam encadeadas com as outras, que podem acontecer em paralelo ou em sequência.

O PERT (Program Evaluation and Review Technique ou Avaliação de Programa e Técnica de Revisão) surgiu no planejamento e controle de programas de defesa da marinha Norte-Americana e também da construção civil no anos 50, como o projeto do míssil Polaris que terminou dois anos antes da data programada. Já o CPM (Critical Path Method ou Método do caminho Crítico) foi desenvolvido como uma técnica de programação para construção, manutenção e desativação de fábricas de processos químicos entre os anos de 1957 e 1958 (QUEZADO et al, 1999).

Segundo PMBOK GUIDE, 1996 apud Marques Junior, 2000, o PERT/CPM é uma técnica que utiliza uma abordagem probabilística e uma abordagem determinística em relação a duração das atividades do projeto. Para Copatto e Souza (2003), PERT/CPM é uma ferramenta de análise de tempos, custos e recursos. Uma representação gráfica do projeto, no qual, as atividades são representadas por flechas ou blocos e indicam suas relações com as atividades mais importantes do projeto. "As redes PERT/CPM permitem representar a sequência em que todas as atividades devem ser executadas." O PERT/CPM é um modelo para planejamento, programação e controle de um empreendimento, operação ou projeto e, tem como principal característica, indicar a sequência operacional que possui a maior duração (CUK, 1978 apud KIENEN, 2000).

O PERT/CPM auxilia o Planejamento e Controle da Produção, pois (TUBINO, 2009):

- Permite uma visão gráfica das atividades;

- Fornece uma estimativa de tempo de duração de cada atividade e, consequentemente, do projeto como um todo;

- Permite uma visão gráfica das atividades que críticas que podem gerar gargalos e atrasar a conclusão do projeto;

- Apresenta quanto tempo de folga tem cada atividade não crítica, o que pode ajudar na redução da alocação de recursos e, assim, redução de custos.

\subsection{Planejamento e gestão da capacidade}

Proto e Mesquita (2003) afirmam que o planejamento da capacidade produtiva da empresa é uma das atividades de grande importância para o planejamento estratégico. Desta forma, planejar investimentos em capacidade envolve decisões estratégicas de longo prazo, considerando aspectos operacionais e financeiros. Correa et al. (2011) afirma que o planejamento de capacidade é desenvolvido com base no horizonte de planejamento almejado pela organização a longo, médio e curto prazos.

Uma capacidade produtiva inferior à demanda existente leva a perda de qualidade do nível de serviço oferecido ao cliente por gerar não atendimento dos prazos, baixa da confiabilidade do produto, aumento dos estoques em processo, entre outros. Em contrapartida, um excesso de capacidade gera custos adicionais e desnecessários (CORREA et al., 2011). "O sucesso de um sistema de estoques depende de um correto planejamento de capacidade" (GELDERS \& WASSENHOVE, 1985 apud ARAÚJO, 2009).

Planejar a capacidade gera uma melhor alocação dos recursos diminuindo as perdas e amentando a utilização desses recursos. (ARAÚJO, 2009).

Assim, o autor explica que o planejamento de capacidade de longo prazo, ao nível do S\&OP, é tratado como Resource Requirements Planning (RRP) e é responsável por antecipar a necessidades

Persp. online: exatas. \& eng, Campos dos Goytacazes, 10 (4), 43-65, 2014

seer.perspectivasonline.com.br 
de capacidade de recursos que requerem um prazo longo para obtenção ou mobilização e auxiliar as decisões da quantidade a ser produzida das famílias de produtos.

O planejamento de capacidade de médio prazo, ao nível do planejamento-mestre da produção, é chamado de Rough Cut Capacity Planning (RCCP) e é responsável por antecipar as necessidades de capacidade de recursos que necessitam de prazos menores para a obtenção ou mobilização, gerar um plano de produção de produtos finais que serão oferecidos aos clientes e dar subsídio ás decisões da quantidade a ser produzida de cada produto.

E o planejamento de capacidade de curto prazo, ao nível do MRP, chama-se Capacity Requirements Planning (CRP). Este é responsável por antecipar as necessidades de capacidade de recursos que requerem um curto prazo para sua obtenção ou mobilização e Promover um plano de produção e compras que seja acessível para que este seja operacionalizado.

\subsection{Gestão de demanda}

Segundo Ballou, (2001) apud Alves, (2006), fazer previsão de demanda é de suma importância para a empresa porque esta fornece informações básicas para o planejamento e controle da produção, bem como logística, marketing, produção, suprimentos e finanças. Os níveis de demanda afetam diretamente a capacidade da empresa, nas necessidades financeiras e na estrutura da organização como um todo.

A previsão de demanda é a principal fonte de informação utilizada pelo PCP na elaboração e controle de suas atividades e assim, auxiliam a empresa no planejamento do sistema produtivo, ou seja, na elaboração do plano de produção, definindo quais produtos e/ou serviços oferecer, qual tipo de mão-de-obra buscar, que tipos de equipamentos e instalações dispor, entre outros (TUBINO, 2009). Makridakis et al. (1998) apud Consul e Werner (2010) destacam que as previsões de demanda devem dar assistência ao planejamento.

Estas previsões também auxiliam na elaboração da utilização do sistema produtivo, decisões de médio e curto prazo no âmbito do planejamento-mestre e programação da produção, envolvendo a utilização dos recursos produtivos disponíveis, definição do plano de produção, compras e reposição de estoques, armazenagem e sequenciamento da produção (TUBINO, 2009).

\subsection{Sistemas produtivos}

Segundo Boiko et al., (2009), classificar os sistemas de produção auxiliam os profissionais de engenharia de produção a ter um melhor entendimento sobre as relações entre cada sistema, a escolha de ferramentas e máquinas para utilização, melhor análise sobre problemas típicos e suas respectivas soluções e, também, análise de técnicas de planejamento e controle da produção, controle da qualidade, previsão de demanda, entre outros.

O autor Tubino (2009) classifica os sistemas produtivos de acordo com a natureza do produto (manufatura de bens ou prestação de serviço) ou com o tipo de operação (contínuos, repetitivos em massa, repetitivos em lotes, sob encomenda).

Existe uma enorme divergência entre a classificação dos sistemas produtivos dada pelos autores, porém o sistema produtivo que atende ao respectivo trabalho é o sistema sob encomenda. Para Tubino (2009), os sistemas produtivos sob encomenda são montados para atender a necessidades específicas dos clientes, ou seja, há uma alta flexibilidade dos recursos produtivos para o atendimento com foco na necessidade do cliente, geralmente com baixa demanda.

Para o cliente, é necessário que o planejamento e controle da produção informe em que data o sistema produtivo atenderá o projeto negociado (TUBINO, 2009). No sistema de produção sobe encomenda, o principal problema enfrentando pelo Planejamento e Controle da Produção é sequenciar as atividades, conciliando a taxa de utilização dos recursos produtivos com o prazo de entrega

Persp. online: exatas. \& eng, Campos dos Goytacazes, 10 (4), 43-65, 2014

seer.perspectivasonline.com.br 
acordado com o cliente e, em caso de não cumprimento deste prazo, o cliente pode suspender o pedido, aderindo outro fornecedor ou multar a empresa (QUEZADO et al., 1999).

\section{ESTUDO DE CASO}

\subsection{A empresa}

O objeto de estudo deste trabalho é um empresa multinacional que atua na área de petróleo e gás realizando manutenções em equipamento offshore cujo seu objetivo principal é criar soluções em tecnologia para a indústria de energia. Desta forma, o foco da análise será direcionado à manutenção de sistemas submarinos, um dos negócios da empresa e seu campo de atuação é a área de exploração e produção, como mostra a figura abaixo.

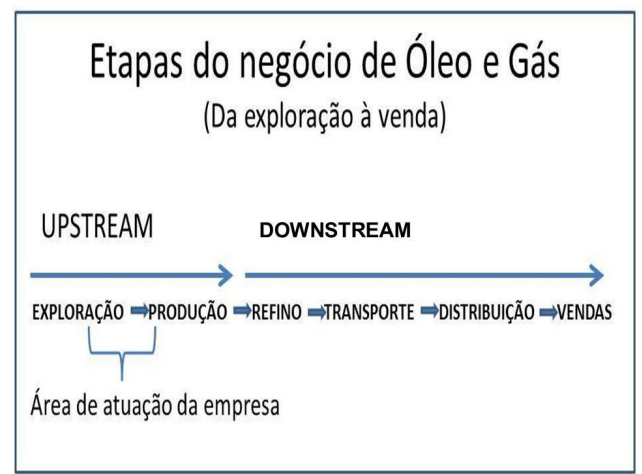

Figura 2: Etapas do negócio de óleo e gás. Fonte: Elaboração própria, 2012.

Esta empresa está situada em diversos países, com instalações nas principais bacias de águas profundas, sendo estas instalações divididas em unidades de fabricação e base de serviço. O presente trabalho tratará somente da base de serviço localizada em Macaé/RJ.

A função deste posto de trabalho é realizar manutenções nos equipamentos que foram vendidos aos clientes pelas unidades de fabricação, como um serviço de aftermarket. Um dos negócios, cujo será o foco do estudo, é a manutenção de sistemas submarinos, que são compostos por vários equipamentos para a área de exploração e produção de petróleo e gás. Este contrato atende à realização do serviço de manutenção em cinco sistemas e, também, o serviço de assistência técnica durante a operação.

\subsection{Descrição do processo de manutenção}

Ao chegar à base, o equipamento passa por uma inspeção de recebimento para verificação de seu estado geral. Após a execução desta inspeção, o equipamento seguirá para a área de testes ou para a armazenagem.

A definição do tipo de manutenção que será realizada obedece ao plano de manutenção, que é um documento gerado pela empresa e avaliado pelo cliente que descreve todos os equipamentos do contrato e limita o tipo de manutenção de acordo com o tempo em que o equipamento ficou operando (medido em meses), número de utilizações do equipamento (medido em descidas e subidas da coluna) e pelo tempo de armazenamento (medido em meses). A manutenção pode ser ainda solicitada pelo cliente ou quando for verificado algum dano durante a operação.

Desta forma, torna-se necessário destacar a definição de Manutenção Preventiva e Corretiva adotada pela empresa.

Manutenção preventiva - manutenção periódica ou ocasional que tenha como finalidade a operacionalidade do equipamento e consiste nas seguintes atividades:

Persp. online: exatas. \& eng, Campos dos Goytacazes, 10 (4), 43-65, 2014

seer.perspectivasonline.com.br 
- Inspeção visual das partes externas;

- Substituição dos elementos de vedação externos;

- Lubrificação das partes externas;

- Substituição de fluidos hidráulicos;

- Limpeza geral;

- Teste funcional;

- Verificação de isolamento e continuidade em cabos elétricos.

Manutenção Corretiva - manutenção que tenha como finalidade restaurar a perfeita operacionalidade do equipamento e consiste nas seguintes atividades:

- Desmontagem geral do equipamento;

- Inspeção por ensaios não destrutivos;

- Upgrade;

- Suporte de engenharia;

- Fornecimento de peças;

- Armazenamento e guarda;

- Gerenciamento da manutenção;

- Prestação dos serviços de apoio;

- Procedimento escrito;

- Registro de relatório;

- Rastreabilidade;

- Limpeza das linhas.

Quando o equipamento entra em manutenção é liberada uma ordem de serviço, gerada através do sistema SAP, contendo as operações necessárias para a realização da manutenção. Essa ordem de serviço passa por um banco de dados que armazena e contabiliza todas as horas de todas as ordens de serviço que serão disponibilizadas para a produção no dia, o pré-sequenciamento.

Esse pré-sequenciamento permite uma melhor visualização da carga de serviço alocada para a produção, bom como uma melhor definição dos serviços que são prioridade, pois atenderão a embarque, de forma a otimizar a utilização dos recursos compartilhados da fábrica (recursos compartilhados por todos os contratos) como área de testes, ponte-rolante, empilhadeiras, guindastes, entre outros.

Se durante o teste ou a manutenção preventiva for encontrado algum tipo de avaria, esta será reportada em um relatório de avarias. Quando o equipamento já entra para fazer a manutenção corretiva, primeiramente é realizada a desmontagem geral do mesmo e as avarias também são reportadas no relatório de avarias.

O relatório de avarias é um documento que descreve todas as avarias encontradas nos componentes do equipamento e os respectivos reparos que deverão ser realizados. Este documento é feito pela produção, avaliado e assinado pela engenharia da empresa e pelo cliente.

As peças descritas neste relatório podem ser classificadas como:

- Reparo;

- Fabricação (interna ou terceirizada);

- Comercial (fornecimento da contratada);

- Peças que serão reutilizadas.

Após a confecção do relatório de avarias, o mesmo será encaminhado para o planejamento que andará com o processo de compra, fabricação e reparo dos itens.

Persp. online: exatas. \& eng, Campos dos Goytacazes, 10 (4), 43-65, 2014 
As peças de reparo serão encaminhadas para o processo de reparo; As peças de fabricação ou comerciais entrarão no cálculo do MRP para que o setor de suprimentos faça os pedidos para que estas sejam compradas ou fabricadas; As peças que serão reutilizadas serão armazenadas.

Quando todas as peças estiverem disponíveis no estoque e reparadas, as mesmas serão reunidas para que a produção faça a montagem e o teste do equipamento para posterior liberação.

\subsection{Planejamento e controle da produção}

A empresa utiliza o planejamento e controle da produção para coordenar e otimizar a utilização dos recursos produtivos de forma a atender os planos estratégico, tático e operacional, como mostra a figura 14 abaixo.

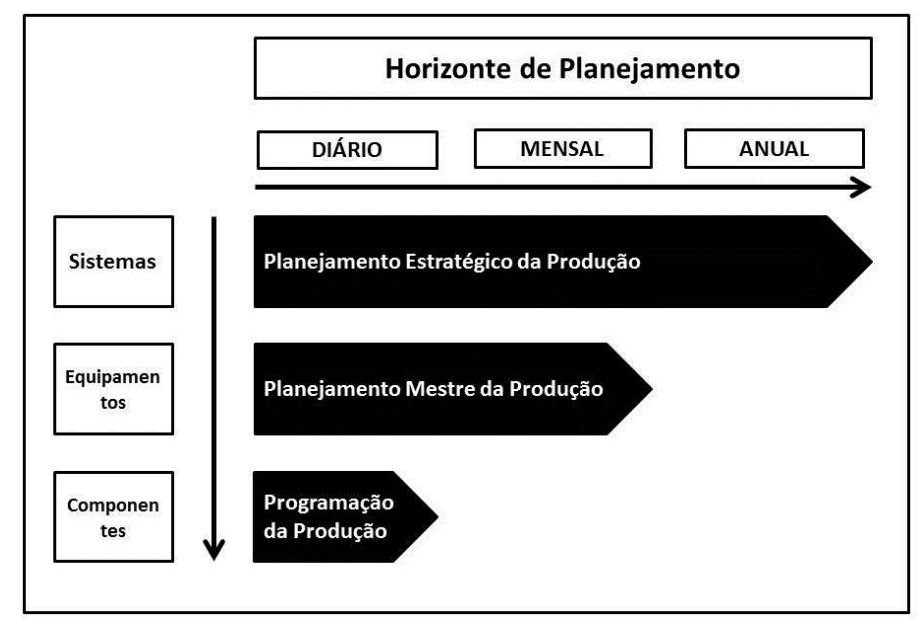

Figura 3: Planejamento Hierárquico da produção. Fonte: Adaptado de Giacon, 2010.

No planejamento estratégico da produção, a empresa define a longo prazo as estratégias para definir ser posicionamento no mercado através do atendimento de sua demanda. Desta forma, através de uma reunião com a diretoria, são apresentadas as famílias de produtos que serão liberadas a longo prazo, ou seja, os sistemas que serão liberados a longo prazo para o cliente.

É necessário destacar que o negócio da empresa que está sendo citado neste estudo, trabalha com a manutenção de sistemas submarinos da área de exploração e produção de petróleo e gás e que são compostos por vários equipamentos. Assim, o que é interessante para o cliente e ter sistemas liberados para operar e não apenas equipamentos liberados aleatoriamente.

Neste nível de planejamento também é feita a previsão das manutenções a longo prazo. Tal previsão é feita com base na situação atual de cada equipamento (liberado, embarcado, em manutenção ou em programação de entrar em manutenção) e no plano de manutenção que define o prazo para que cada tipo de manutenção seja realizado em cada equipamento que compõe o sistema.

Este planejamento unido ao planejamento dos outros contratos, permite que a engenharia de planejamento da empresa planeje a capacidade de produção da organização a longo prazo.

Mensalmente a engenharia de planejamento realiza reuniões com a administração dos contratos para avaliar se houve ou se deverá ser feita alguma modificação na previsão das manutenções, atendendo ao planejamento de médio prazo. Porém, por falta de prévio planejamento de estoques, de recursos necessários para desmontagem, montagem e teste dos equipamentos, falta de planejamento na utilização da capacidade produtiva. Assim, a empresa enfrenta problemas como:

- Não atendimento ao cliente nos prazos estabelecidos;

- Equipamentos com a manutenção paralisada por falta de material;

- Falta de serviço para a produção, por ter equipamentos com a manutenção paralisada;

Persp. online: exatas. \& eng, Campos dos Goytacazes, 10 (4), 43-65, 2014

seer.perspectivasonline.com.br 
- Ambiente onde tudo se torna urgência;

- Liberação de ordens de serviço de forma aleatória para gerar mão-de-obra promovendo, então, a liberação de equipamentos de forma também aleatória;

- Gargalos nos setores de caldeiraria, pintura e logística no atendimento ás emergências.

\subsection{Utilização da ferramenta PERT/CPM}

Para realizar a análise da utilização da técnica PERT/CPM, foram listadas as atividades referentes à manutenção do equipamento escolhido, a duração de cada uma e suas respectivas relações de precedência, formando a tabela 2 :

Tabela 2: Descrição das atividades, suas durações e relações de precedência.

\begin{tabular}{|c|l|c|c|}
\hline ATIVIDADE & \multicolumn{1}{|c|}{ DESCRIÇÃO) } & TEMPO & ANTECEDENTE \\
\hline A & Requisitar Equipamento (mover para a fábrica) & $24 \mathrm{~h}$ & - \\
\hline B & Manutenção Preventiva & $41 \mathrm{~h}$ & $\mathrm{~A}$ \\
\hline C & Fazer relatório de Avarias & $24 \mathrm{~h}$ & $\mathrm{~B}$ \\
\hline D & Alocar peças na ordem & $24 \mathrm{~h}$ & $\mathrm{C}$ \\
\hline E & Fazer ordem de reparo do equipamento & $24 \mathrm{~h}$ & $\mathrm{C}$ \\
\hline F & Fazer ordem de reparo das peças & $24 \mathrm{~h}$ & $\mathrm{C}$ \\
\hline G & Processo de reparo das peças & $336 \mathrm{~h}$ & $\mathrm{~F}$ \\
\hline H & Comprar/fabricar peças de substituição & $720 \mathrm{~h}$ & $\mathrm{D}$ \\
\hline I & Desmontagem localizada do equipamento & $13 \mathrm{~h}$ & $\mathrm{E}$ \\
\hline J & Enviar itens de reparo e de substituição para a fábrica & $8 \mathrm{~h}$ & $\mathrm{G}, \mathrm{H}$ \\
\hline K & Montagem localizada do equipamento & $18 \mathrm{~h}$ & $\mathrm{I}, \mathrm{J}$ \\
\hline L & Teste Geral do equipamento & $52 \mathrm{~h}$ & $\mathrm{~K}$ \\
\hline M & Caldeiraria do equipamento & $6 \mathrm{~h}$ & $\mathrm{E}$ \\
\hline N & Pintura localizada do equipamento & $10 \mathrm{~h}$ & $\mathrm{M}$ \\
\hline O & Liberação do equipamento & $2 \mathrm{~h}$ & $\mathrm{~B}, \mathrm{~L}, \mathrm{~N}$ \\
\hline P & Realizar armazenagem & $2 \mathrm{~h}$ & $\mathrm{O}$ \\
\hline
\end{tabular}

Fonte: Elaboração própria, 2012.

Tendo estas informações sobre as atividades e conhecendo as relações de precedência, será construído diagrama de rede PERT utilizando os nós para representar as atividades e os arcos para representar as relações de precedência, conforme foi construído abaixo:

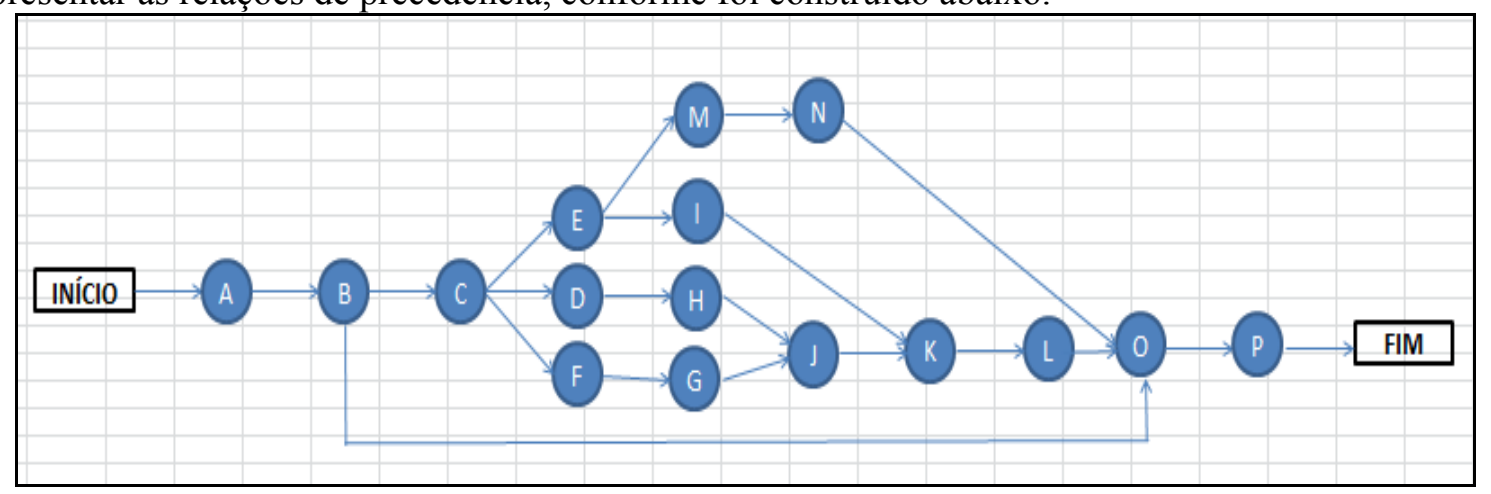

Figura 4: Diagrama de rede PERT. Fonte: Elaboração própria, 2012.

Com base neste primeiro diagrama de rede, ou seja, através da construção do PERT foram definidos todos os caminhos para a realização da manutenção do equipamento, conforme mostram as figuras $16,17,18,19$ e 20 abaixo:

Persp. online: exatas. \& eng, Campos dos Goytacazes, 10 (4), 43-65, 2014 


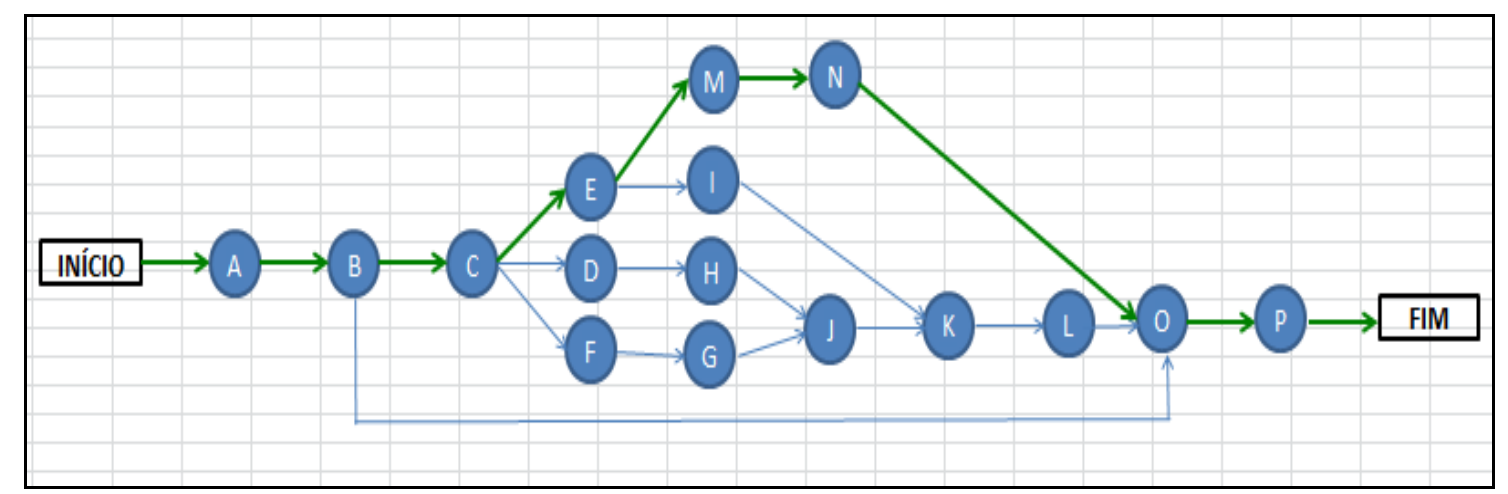

Figura 5: Caminho 1 do processo de manutenção. Fonte: Elaboração própria, 2012.

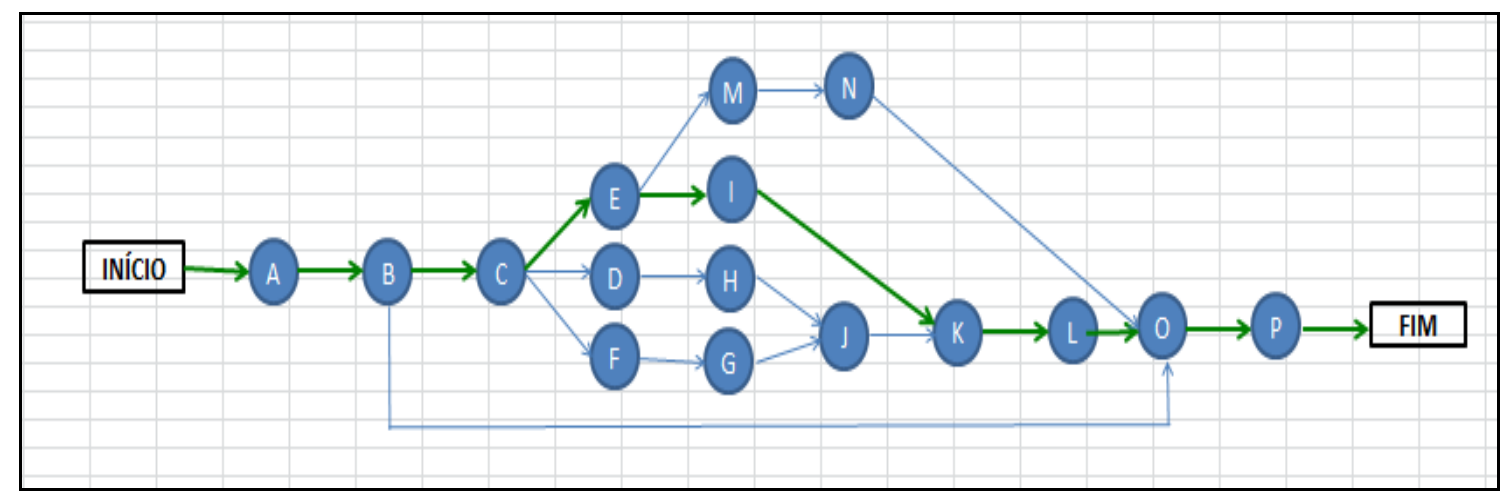

Figura 6: Caminho 2 do processo de manutenção. Fonte: Elaboração própria, 2012.

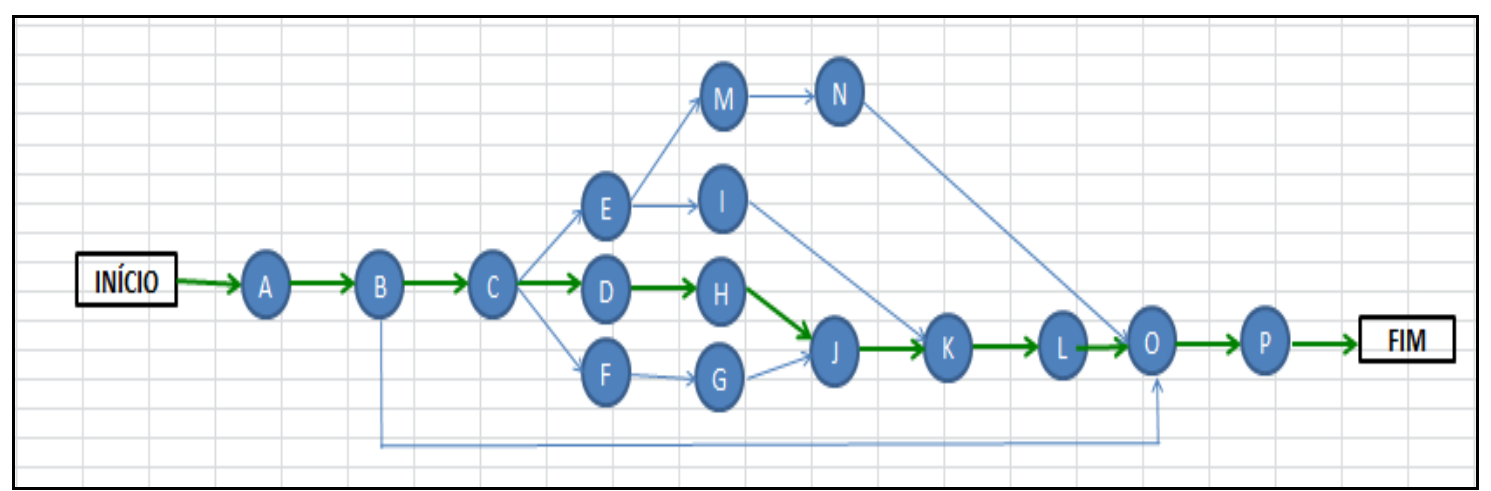

Figura 7: Caminho 3 do processo de manutenção. Fonte: Elaboração própria, 2012.

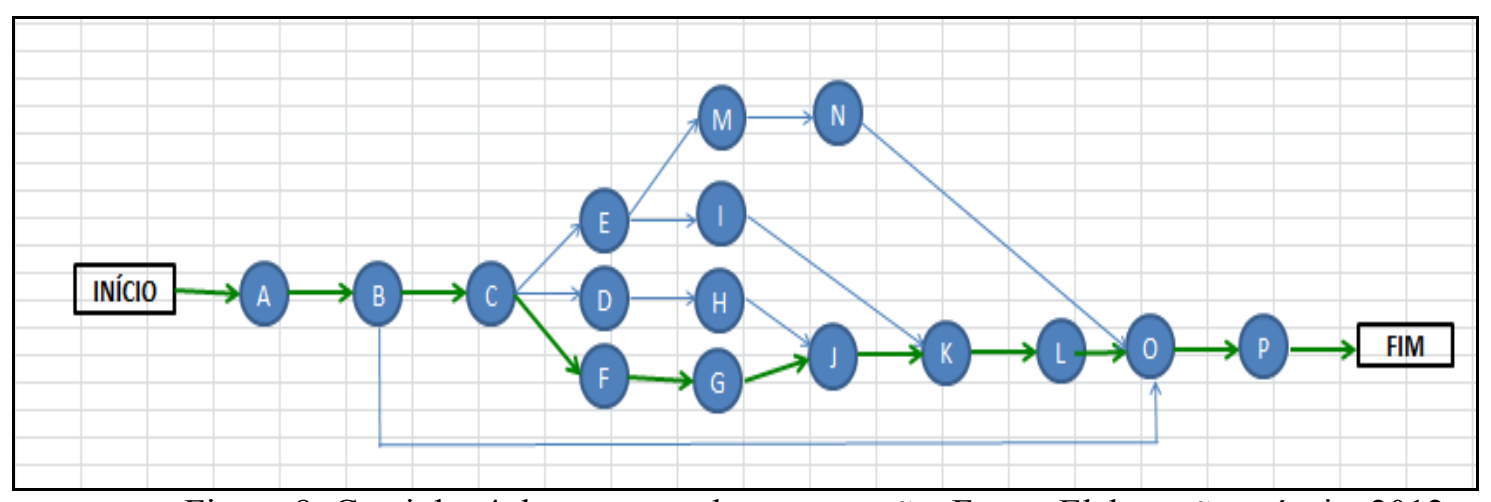

Figura 8: Caminho 4 do processo de manutenção. Fonte: Elaboração própria, 2012.

Persp. online: exatas. \& eng, Campos dos Goytacazes, 10 (4), 43-65, 2014 seer.perspectivasonline.com.br 


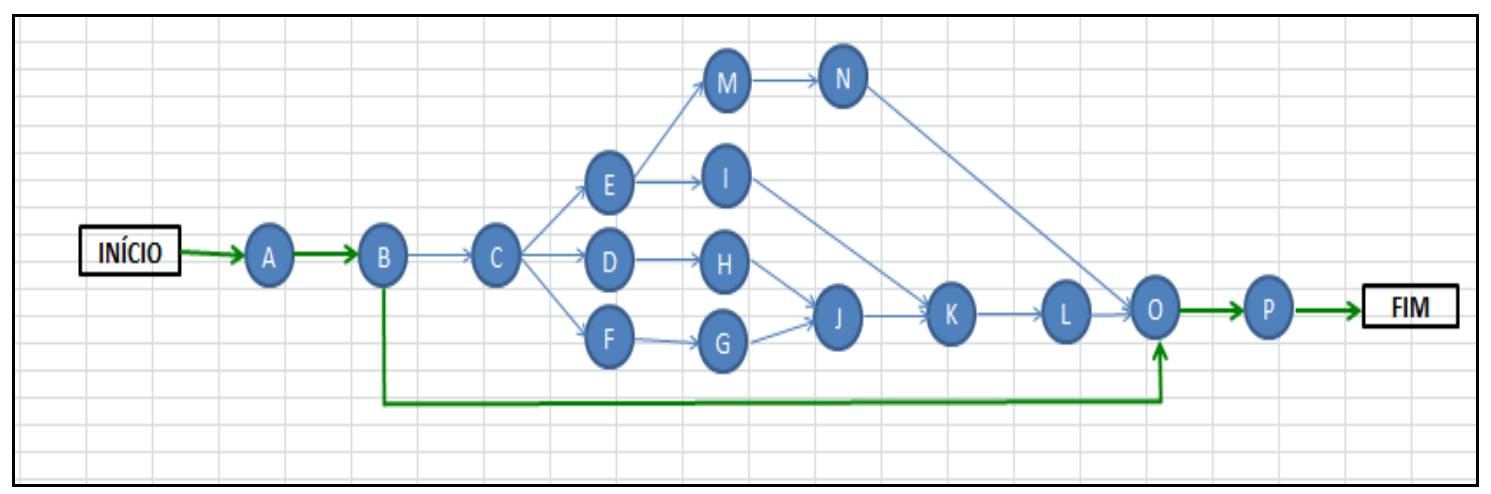

Figura 9: Caminho 5 do processo de manutenção. Fonte: Elaboração própria, 2012.

Uma das maneiras de se calcular o caminho mais longo, ou seja, o caminho considerado o mais crítico, seria somando as durações de todas as atividades com base nos diagramas apresentados anteriormente, conforme mostra a tabela abaixo:

Tabela 3: Duração do caminho crítico.

\begin{tabular}{|c|l|c|}
\hline \multicolumn{2}{|c|}{ CAMINHO CRÍTICO } & COMPRIMENTO (Horas) \\
\hline 1- & Início - $\mathrm{A}+\mathrm{B}+\mathrm{C}+\mathrm{E}+\mathrm{M}+\mathrm{N}+\mathrm{O}+\mathrm{P}-$ Fim & 133 \\
\hline 2- & Início - $\mathrm{A}+\mathrm{B}+\mathrm{C}+\mathrm{E}+\mathrm{I}+\mathrm{K}+\mathrm{L}+\mathrm{O}+\mathrm{P}-$ Fim & 200 \\
\hline 3- & Início - $\mathrm{A}+\mathrm{B}+\mathrm{C}+\mathrm{D}+\mathrm{H}+\mathrm{J}+\mathrm{K}+\mathrm{L}+\mathrm{O}+\mathrm{P}-$ Fim & 515 \\
\hline 4- & Início - $\mathrm{A}+\mathrm{B}+\mathrm{C}+\mathrm{F}+\mathrm{G}+\mathrm{J}+\mathrm{K}+\mathrm{L}+\mathrm{O}+\mathrm{P}-$ Fim & 69 \\
\hline 5- & Início - $\mathrm{A}+\mathrm{B}+\mathrm{O}+\mathrm{P}-$ Fim & 69 \\
\hline
\end{tabular}

Fonte: Elaboração própria, 2012.

Sendo o caminho crítico, o caminho mais longo, determinou-se que o caminho três é o caminho mais crítico do processo de manutenção. Esta análise mostra que o tempo requerido para completar o processo de manutenção é de 915 (novecentos e quinze) horas, ou seja, aproximadamente 39 (trinta e nove) dias. A figura 21 abaixo destaca o caminho crítico:

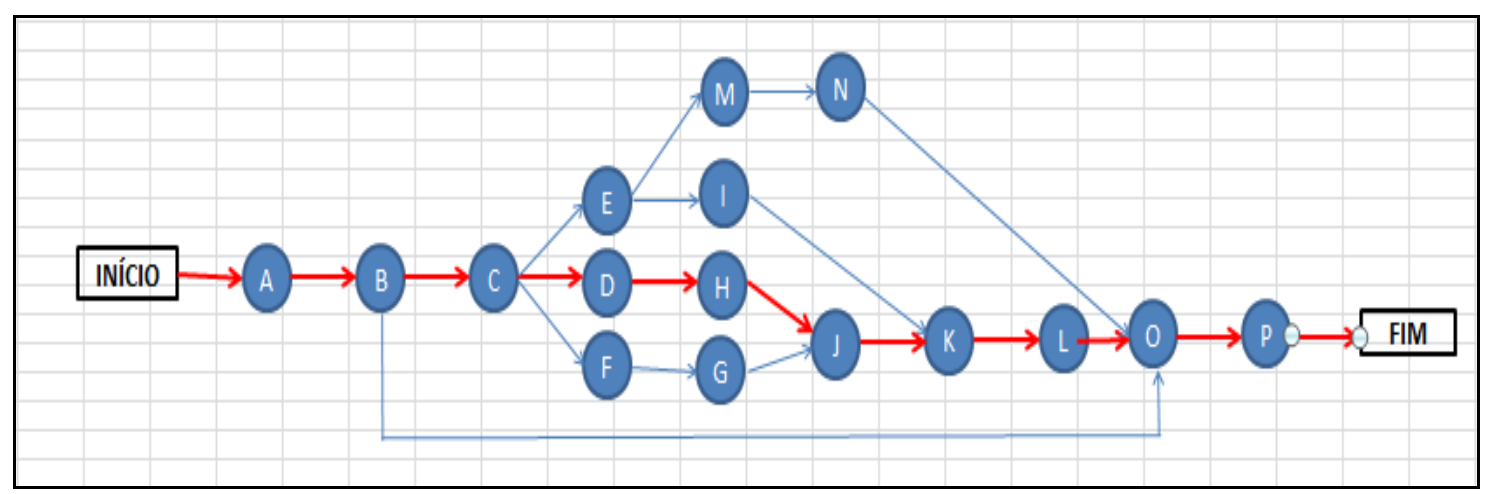

Figura 10: Caminho crítico do processo de manutenção. Fonte: Elaboração própria, 2012.

Para calcular o caminho crítico através do CPM, foram utilizadas as variáveis abaixo que anteriormente já foram citadas:

Persp. online: exatas. \& eng, Campos dos Goytacazes, 10 (4), 43-65, 2014 seer.perspectivasonline.com.br 
- ES - Tempo Inicial Mais Cedo;

- EF - Tempo Final Mais Cedo;

- LS - Tempo Inicial Mais Tarde;

- LF - Tempo Final Mais Tarde.

Também foi calculado o tempo de folga entre as atividades. Esse tempo de folga permite que uma atividade atrase, ou seja, adiantada sem comprometer o tempo estimado para a manutenção do equipamento e será mostrado da seguinte forma:

\begin{tabular}{|c|c|}
\hline \multicolumn{2}{|c|}{ FOLGA } \\
\hline ES & EF \\
\hline LS & LF \\
\hline
\end{tabular}

Abaixo está apresentado o diagrama PERT, o cálculo do CPM e, também, o cálculo das folgas entre as atividades, apresentando, também, a programação das atividades, sou seja, alocação das tarefas do projeto na ordem temporal que devem ser executadas.

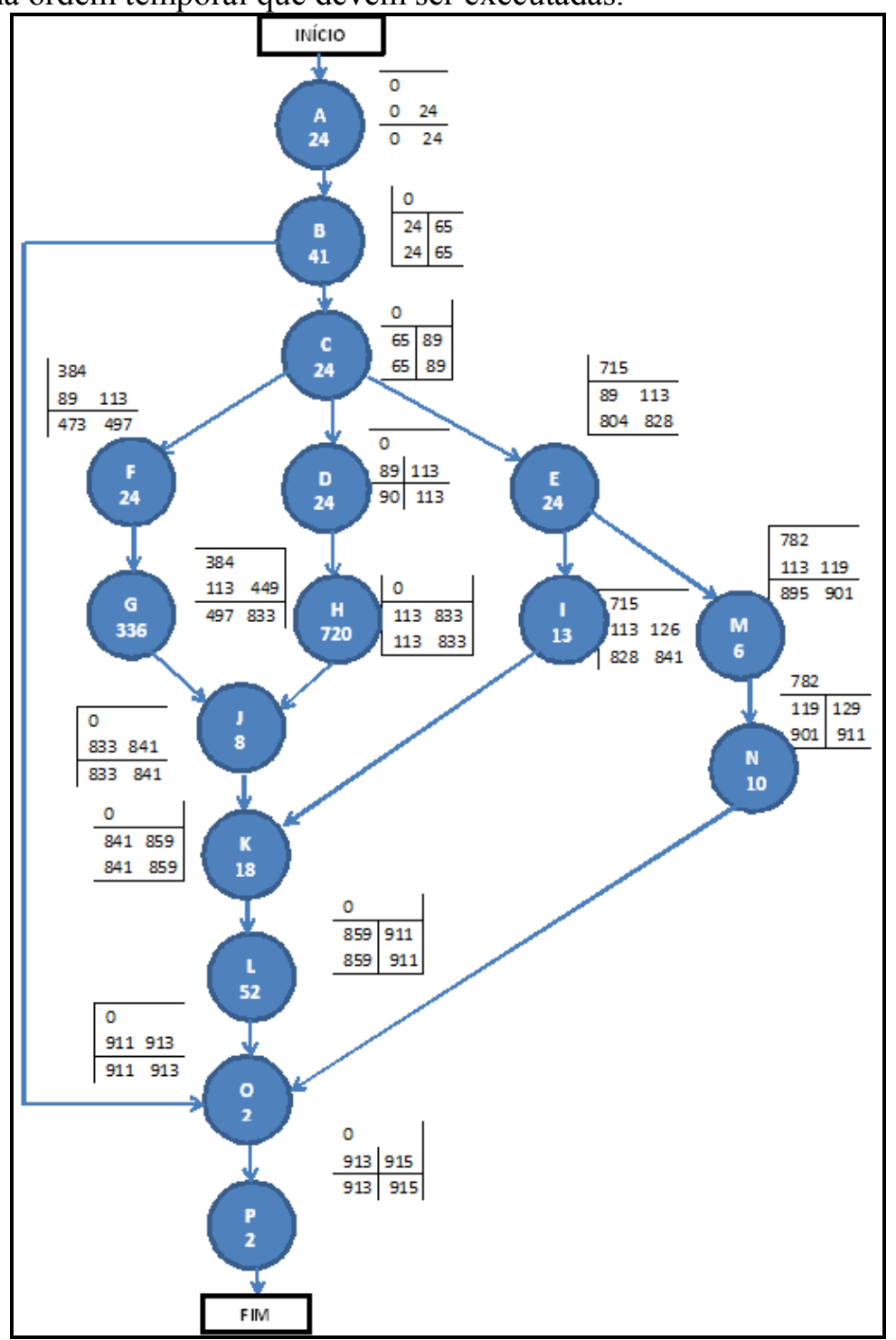

Figura 11: Cálculo do PERT/COM. Fonte: Elaboração própria, 2012.

Persp. online: exatas. \& eng, Campos dos Goytacazes, 10 (4), 43-65, 2014

seer.perspectivasonline.com.br 
Essa análise permitiu verificar que as atividades que não tem folga são as atividades que compõem o caminho crítico para a realização da manutenção do equipamento de forma que qualquer tipo de atraso de alguma dessas atividades pode comprometer a liberação do equipamento no tempo estimado e, consequentemente, o atraso da sua entrega para o cliente. Conforme já foram descritas anteriormente, estas atividades são:

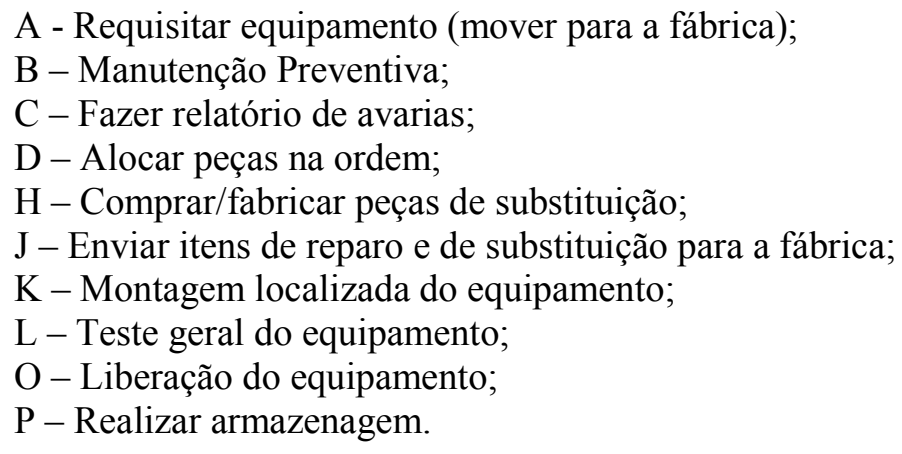

A partir desta análise, pode-se verificar que:

As atividades F e G, apesar de não estarem no caminho crítico, devem ser controladas para não ultrapassarem o tempo de folga de 384 horas de forma a não atrasar uma atividade do caminho crítico que é a atividades $\mathrm{J}$, pois esta só acontece se todas as peças (tanto de reparo quanto de fabricação e compra) estiverem disponíveis. Isso atrasaria, também, a montagem localizada do equipamento, atrasando todo o restante do projeto. Pode-se destacar, também, que a atividade $\mathrm{G}$ pode atrasar até o final mais tarde da atividade $\mathrm{H}$, já que as peças de reparo, de compra e de fabricação devem estar ao mesmo tempo na fábrica, o que compõe a atividade $\mathrm{J}$, que por sua vez está ligada à atividade $\mathrm{K}$ que é a montagem do equipamento.

A atividade $\mathrm{H}$ é uma atividade do caminho crítico e, como já foi dito anteriormente, uma das maneiras de evitar o atraso dessa atividade seria, através do planejamento de S\&OP, planejar as manutenções que serão realizadas a longo prazo e ter um estoque de segurança para os sobressalentes que mais são utilizados no processo e para este equipamento.

Caso houvesse alguma restrição na área de testes que impedisse que o equipamento fosse testado no momento estabelecido na rede, uma das soluções seria adiantar as operações de caldeiraria e pintura a fim de que não se perca tempo e que isso atrase a liberação do equipamento.

O diagrama elaborado mostrou a dificuldade de realocar, antecipar ou adiar uma atividade do projeto, além da folga calculada, pois as atividades estão bem inter-relacionadas, evidenciando a necessidade de um maior controle sobre as mesmas para que não ultrapasse os tempos de duração, e, para que o equipamento seja entregue na data acordada com o cliente em perfeita condições de funcionamento.

\section{Conclusão}

Um sistema produtivo será tão eficiente quanto a forma que resolve seus problemas administrativos, de planejamento, programação e controle (TUBINO, 2009). A técnica PERT/CPM, da mesma maneira que os objetivos estratégicos da organização, visa rapidez e pontualidade, sendo estas, características de um sistema produtivo eficiente (QUEZADO et. al., 1999).

A utilização da técnica PERT/CPM, através da programação das atividades de manutenção, dá suporte ao nível operacional da empresa, ou seja, estabelecendo quando começar e terminar uma atividade. Gerenciando estas atividades e entregando os equipamentos no prazo, evita gargalos e problemas no nível tático, fazendo com que o planejamento-mestre da produção tenha que ser refeito

Persp. online: exatas. \& eng, Campos dos Goytacazes, 10 (4), 43-65, 2014

seer.perspectivasonline.com.br 
por causa do mau planejamento e execução do operacional. Tudo isso influencia o planejamento estratégico da empresa que busca atender a demanda, atingir critérios de desempenho e alcançar o que foi definido na sua missão.

Foi percebido que um mau gerenciamento das atividades ocasiona paralisação da manutenção do equipamento, esta paralisação gera custos para a empresa, perda de capacidade produtiva como espaço físico, influenciando o planejamento de capacidade previamente estabelecido, a mão-de-obra fica ociosa e ocorre atraso na liberação do equipamento podendo a empresa ficar sujeita a multa pelo cliente.

É necessário destacar que se verificou, também, que a ação de planejar e programar é importante para que o setor que irá realizar a próxima atividade se prepare para que a mesma possa ser atendida e que caso haja algum problema, que este seja verificado antes que o processo paralise.

Desta forma, torna-se importante utilizar uma técnica para planejar, programar e controlar as atividades de manutenção, já que o objetivo da mesma é deixar o equipamento funcional e disponível para o cliente operar, pois quando o equipamento é entregue no prazo e com qualidade, gera maior valor e confiabilidade do cliente em relação ao serviço prestado, aumenta a disponibilidade dos equipamentos, aumenta o faturamento e o lucro da empresa, aumenta a procura de clientes para o serviço, o que reduz custos, mantém a fábrica produtiva, garantindo o crescimento da organização e seu posicionamento no mercado competitivo.

Pode-se concluir que o sequenciamento de atividades em um sistema produtivo de processo por projetos, caracterizado por altos lead times produtivos, através da utilização do PERT com a montagem de redes e, também, através do cálculo do CPM, dimensionando tempos, folgas e determinando o caminho crítico do processo, pode auxiliar no gerenciamento das atividades de manutenção de equipamentos submarinos a fim de que a empresa consiga atender aos clientes de forma satisfatória.

\section{REFERÊNCIAS BIBLIOGRÁFICAS}

ALVES, Sérgio. Um processo de gestão de demanda construído sobre os pilares da gestão integrada de negócios. In: SIMPEP, XIII., 2006, Bauru. Internet. Disponível em:< http://www.simpep.feb.unesp.br/anais/anais 13/artigos/665.pdf $>$ Acesso em 13 de setembro de 2012.

ARAÚJO, Larissa. Nivelamento da Capacidade de produção utilizando Quadros Heijunka em Sistemas Híbridos de Coordenação de Ordens de Produção. 2009. 135 p. Dissertação (Mestrado) Escola Politécnica da Universidade de São Paulo, São Paulo, 2009. Internet. Disponível em: $<$ http://www.teses.usp.br/teses/disponiveis/18/18140/tde-08052009-082635/pt-br.php > Acesso em: 03 de setembro de 2012.

BATALHA, Mário Otávio (Org.). Introdução à Engenharia de Produção. [S. 1.]: Elsevier Campus, 2007. 296 p.

BOIKO, Thais et al. Classificação de Sistemas de produção: Uma abordagem de Engenharia de Produção. In: Encontro de Produção Científica tecnológica, IV., 2009. Internet. Disponível em: $<$ http://www.fecilcam.br/nupem/anais iv epct/PDF/engenharias/08 BOIKO TSUJIGUCHI VAROL O.pdf $>$. Acesso em: 24 de outubro de 2012.

BRANCO FILHO, Gil. A organização, o planejamento e o controle da manutenção. [s. L.]: Ciência Moderna, 2008.

CAMPOS JUNIOR, Estevam Elpídio. Reestruturação da área de planejamento, programação e controle na gerência de manutenção portuária - CVRD. 2006. 76 f. Monografia (Graduação) -

Persp. online: exatas. \& eng, Campos dos Goytacazes, 10 (4), 43-65, 2014

seer.perspectivasonline.com.br 
Universidade Estadual Do Maranhão Centro De Ciências Tecnológicas Curso De Engenharia Mecânica, São Luis, 2006.

CHIOCHETTA, João Carlos; HATAKEYAMA, Kazuo; MARÇAL, Rui Francisco Martins. Sistema de Gestão da Manutenção para a Pequena e Média Empresa. XXIV Encontro Nacional de Engenharia de Produção. Florianópolis, 3 de nov. 2004.

CONSUL, Fabrício; WERNER, Liane. Avaliação de técnicas de previsão de demanda utilizadas por um software de gerenciamento de estoques no setor farmacêutico. In: ENEGEP, XXX, 2010, São Carlos. Internet. Disponível em: $\leq \mathrm{http} / / /$ www.abepro.org.br/biblioteca/enegep2010 TN_STO 113 740_15746.pdf $>$ Acesso em $03 \mathrm{de}$ setembro de 2012.

COPATTO, Alexandre Sanches; SOUZA, Fernando Bernardi de. PERT/CPM versus Corrente Crítica: Pressupostos e Implicações. Xxiii Encontro Nac. de Eng. de Produção. Ouro Preto, out. 2003. Internet. Disponível em: www.abepro.org.br/biblioteca/ENEGEP2003_TR0504_1638.pdf>.

CORREA, Henrique Luiz; GIANESI, Irineu Gustavo Nogueira; CAON, Mauro. Planejamento, programação e controle da produção. 5. ed. São Paulo: Atlas S.a., 2011. 434 p.

DANTAS, Murilo; TÁVORA JÚNIOR, José. Planejamento estratégico da automação industrial em uma perspectiva de alinhamento estratégico. In: ENEGEP, XXIII, 2003, Ouro Preto. Internet. Disponível em: $<$ http://www.abepro.org.br/biblioteca/ENEGEP2003 TR0702 1694.pdf $>$ Acesso em: 13 de outubro de 2012.

KARDEC, Alan; LAFRAIA, João Ricardo. Gestão Estratégica e Confiabilidade. Rio de Janeiro: Qualitymark, 2002.

KIENEN, Anísio. Protótipo de uma ferramenta de software baseada na metodologia PERT/CPM para o planejamento de projeto de desenvolvimento de sistemas. 2000. $74 \mathrm{p}$. Monografia (Bacharelado) - Universidade Regional de Blumenau. Blumenau, 2000. Internet. Disponível em: $<$ http://campeche.inf.furb.br/tccs/2000-I/2000-1anisiokienenvf.pdf $>$ Acesso em: 17 de outubro de 2012.

KOPAK, Simone; FAVARETTO, Fábio. Análise comparativa entre modelos conceituais de planejamento e controle da produção com foco nas restrições de capacidade. In: ENEGEP, XXIII, 2003, Ouro Preto. Internet. Disponível em

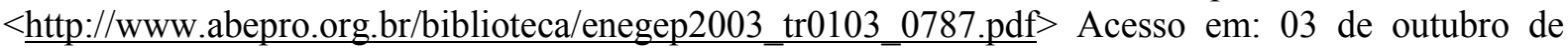
2012.

KREMER, Cristian Dekkers; KOVALESKI, João Luiz. Planejamento e controle dos processos de fabricação metalúrgicos auxiliado pelo gráfico de Gantt: um estudo de caso. XXIV Enegep, Fortaleza, $92006 . \quad$ out. 200 Disponível em: <www.abepro.org.br/.../enegep2008_tn_sto_069_491_12129.pdf>

KREMER, Cristian et al. Verificação da capacidade produtiva obtida através da análise do planomestre da produção: um estudo de caso. In: SIMPEP, XIII., 2006, Bauru. Internet. Disponível em < http://www.simpep.feb.unesp.br/anais/anais 13/artigos/59.pdf> Acesso em: 03 de outubro de 2012.

LAGE JUNIOR, Muris. Os Sistemas de Planejamento e Controle da Produção e o Ambiente: Uma Perspectiva Histórica. Simpep, Bauru, 06 nov. 2006. Interner. Disponível em: $<$ www.simpep.feb.unesp.br/anais/anais_13/artigos/660.pdf $>$. 
MARQUES JUNIOR, Luiz. Uma contribuição para melhoria do planejamento de empreendimentos de construção em organizações públicas. 2000. 125 p. Dissertação (Mestrado) Escola Politécnica da Universidade de São Paulo, São Paulo, 2000. Internet. Disponível em: $<$ http://www.teses.usp.br/teses/disponiveis/3/3136/tde-13072002-175908/pt-br.php > Acesso em: $10 \mathrm{de}$ setembro de 2012.

MELO, Janaina Ferreira Marques de; VILLAR, Antônio de Mello; SEVERIANO FILHO, Cosmo. O posicionamento do Planejamento e Controle da Produção - PCP em uma indústria alimentícia. Xiii Simpep, Bauru, 6 out. 2006. Internet. Disponível em: www.simpep.feb.unesp.br/anais/anais_13/artigos/863.pdf $>$

MENESES, Gustavo; MULLER, Cláudio. Planejamento Estratégico, Avaliação de Desempenho e Gestão por Processos em empresa pública de transporte em massa. In: ENEGEP, XXVI, 2006, Fortaleza.

NAVARRO, Juan; LIMA, Renato. Planejamento de vendas e operações (S\&OP): um estudo de caso em uma empresa da indústria de telecomunicações. In: ENEGEP, XXVI, 2006, Fortaleza. Internet. Disponível em: < $\quad$ http://www.abepro.org.br/biblioteca/ENEGEP2006_TR530354 7746.pdf $>$ Acesso em: 13 de outubro de 2012 .

PETROBRÁS (2009) Internet. Disponível em: www.petrobras.com.br/pt/quem-somos/nossa-historia/

PROTO, Luiz; MESQUITA, Marco Aurélio. Previsão de demanda para planejamento da capacidade de empresa do setor cimenteiro. In: ENEGEP, XXIII, 2003, Ouro Preto. Internet. Disponível em:

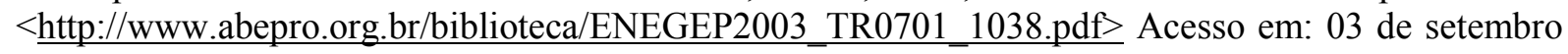
de 2012.

QUEZADO, P. C. M. ; CARDOSO, C. R. O.; TUBINO, D. F. Programação e controle da produção sob encomenda utilizando PERT/CPM e Heurísticas. In: V Congresso Internacional de Engenharia Industrial, XIX ENEGEP, 1999, Rio de Janeiro. Anais. Rio de Janeiro, RJ, 1999. Internet. Disponível em: < http://www.abepro.org.br/biblioteca/ENEGEP1999_A0381.PDF> Acesso em: 01 de novembro de 2012.

SILVA, Edna Lúcia da. MENEZES, Estera Muszkat. Metodologia da pesquisa e elaboração de dissertação. 4. ed. Florianópolis, 2005, p. 139.

SLACK, Nigel; CHAMBERS, Stuart; JOHNSTON, Robert. Administração da Produção. 3. ed. São Paulo: Atlas S.a., 2009. 703 p.

SOARES, Hugo Freneda; PEREIRA, Neocles Alves. Da gestão de demanda ao planejamento de operações: Uma revisão da literatura. Xxvi Enegep, Fortaleza, 9 out. 2006. Internet. Disponível em: www.abepro.org.br/biblioteca/ENEGEP2006_TR450310_7252.pdf $>$

TUBINO, Dalvio Ferrari. Planejamento e Controle da Produção. 2. ed. São Paulo: Atlas S.a., 2009. $190 \mathrm{p}$.

THOMAS, José Eduardo. Fundamentos da Engenharia de Petróleo. 2. ed. [S.l.]: Interciência, 2004. $217 \mathrm{p}$.

UFRRJ (2012): Internet. Disponível em: http://www.ufrrj.br/codep/materialcursos/gerenciamento/gerenciamentotempo/CGPGT_PERT_CPM_FernandoNogueira.pdf

Persp. online: exatas. \& eng, Campos dos Goytacazes, 10 (4), 43-65, 2014

seer.perspectivasonline.com.br 
XAVIER, Júlio. Manutenção Classe Mundial. In: Congresso Brasileiro de Manutenção, 1998, Salvador. Internet. Disponível em: $<$ http://www.tecem.com.br/downloads/manutencao.pdf $>$ Acesso em: 27 de setembro de 2012.

XAVIER, Júlio; PINTO, Alan Kardec. Manutenção: Função estratégica. Rio de Janeiro: Qualitymark, 2001. 